NOTE

\title{
Predation intensity is negatively related to plant species richness in a benthic marine community
}

\author{
Emma R. Moran ${ }^{1, *}$, Pamela L. Reynolds ${ }^{1}$, Laura M. Ladwig², Mary I. O'Connor ${ }^{3}$, \\ Zachary T. Long ${ }^{2,4}$, John F. Bruno ${ }^{1,5}$
}

${ }^{1}$ Department of Biology, University of North Carolina at Chapel Hill, Chapel Hill, North Carolina 27599, USA

${ }^{2}$ Institute of Marine Sciences, University of North Carolina at Chapel Hill, 3431 Arendell Street, Morehead City, North Carolina 28557, USA

${ }^{3}$ Curriculum in Ecology, University of North Carolina at Chapel Hill, Chapel Hill, North Carolina 28599, USA

${ }^{4}$ Department of Biology and Marine Biology, University of North Carolina-Wilmington, 601 South College Road, Wilmington, North Carolina 28403, USA

${ }^{5}$ Department of Marine Sciences, The University of North Carolina at Chapel Hill, Chapel Hill, North Carolina 27599, USA

\begin{abstract}
Plant biodiversity affects primary productivity and resource utilization in terrestrial and aquatic ecosystems, and may also influence other key ecological processes such as predator-prey interactions. We tested the hypotheses that predation intensity is negatively related to plant species richness, and that prey density is positively related to plant species richness. We performed one field and one mesocosm experiment based on a benthic estuarine food web to measure the effects of macroalgal species richness on the predation of a herbivorous amphipod by a carnivorous fish. In the mesocosm experiment, prey mortality was significantly lower in the 5 species algal polyculture than in the average monoculture, suggesting that increasing algal richness decreased predation intensity. In the field experiment, prey colonization and density were positively related to algal richness in the presence of a diverse guild of predators. Combined, these results suggest that primary producer richness can influence animal community structure and food web dynamics, emphasizing the need for biodiversity-ecosystem functioning research in realistic, multitrophic systems.
\end{abstract}

KEY WORDS: Biodiversity $\cdot$ Ecosystem function $\cdot$ Macroalgae $\cdot$ Predation $\cdot$ Species richness

\section{INTRODUCTION}

Plant diversity is often positively and causally related to primary productivity and standing plant biomass (Cardinale et al. 2006). This relationship could lead to strong bottom-up effects on higher trophic levels by increasing food availability and habitat volume (Hutchinson 1959). There is some evidence that plant richness, and dietary diversity in general, can increase consumer fitness, presumably increasing secondary production and penetrating higher trophic levels (Olson et al. 2007).

Plant species richness could also have effects on animal communities by influencing predator-prey interactions and other trophic dynamics. For example, increasing plant species or functional group richness could reduce predation intensity. A likely mechanism would be the resulting increase in habitat complexity (Price et al. 1980, Bruno et al. 2008), which influences predator foraging efficiency and the quality of prey refuges from predators (Heck \& Wetstone 1977, Diehl 1992, Bruno \& Bertness 2001). Increasing plant richness would also likely include plant species that provide effective refuge from predators (Bruno et al. 2003) and could stabilize refuge availability both spatially and temporally via the insurance effect (Yachi \& Loreau 1999).

Plants affect foraging efficiency of predators and parasites (Pimentel 1961, Strong et al. 1984, Andow \& Prokym 1990), and the composition and characteristics 
of plants and other foundation species can influence predation within biogenic habitats (Heck \& Orth 1980, Bruno \& Bertness 2001). There is also substantial descriptive and experimental evidence that plant diversity and productivity are positively related to the richness and abundance of plant community inhabitants (Murdoch et al. 1972, Southwood et al. 1979, Siemann 1998, Siemann et al. 1998). However, there is little known mechanistically about the direct and indirect effects of plant richness on higher trophic levels and food web dynamics.

The purpose of this study was to test the hypothesis that the richness of plants and other foundation species can influence predation within the habitats they form. We performed 2 experiments, one mesocosm and one field, with an estuarine food web to measure the effects of macroalgal species richness on the predation of herbivorous amphipods by a carnivorous fish. Our results suggest that macroalgal richness can significantly affect the predation and density of a dominant herbivore.

\section{MATERIALS AND METHODS}

Mesocosm experiment. We manipulated predator presence and macroalgal identity and richness in a fully factorial design ( $\mathrm{n}=4$, both factors were considered fixed). The experiment took place on June 16, 2007, at the University of North Carolina at Chapel Hill's Institute of Marine Science in Morehead City, North Carolina, USA. Manipulations were performed in $30 \mathrm{l}$ clear polycarbonate outdoor mesocosms, into which filtered seawater from the adjacent Bogue Sound was fed via dump buckets (Bruno \& O'Connor 2005). This aerated the water and approximated the turbulence of local subtidal environments (Duffy \& Hay 2000).

The 6 treatments included 5 algal monocultures and 1 polyculture (which included all 5 species), enabling us to unambiguously partition the relative effects of species identity and richness (Loreau 1998). We used 5 common, co-occurring yet taxonomically and morphologically distinct benthic macroalgae: Dictyota menstrualis, Sargassum filipendula, Padina gymnospora, Gracilaria verrucosa, and Ulva lactuca. Initially, $30.0 \pm$ $0.5 \mathrm{~g}$ of algae was added to each mesocosm in a replacement design (i.e. algal biomass was held constant across richness treatments). The algae were attached with cable ties to $25 \mathrm{~cm} \times 25 \mathrm{~cm}$ Vexar ${ }^{\circledR}$ plastic screens at 5 points per screen, so that the polyculture had 1 attachment point per alga with species arranged haphazardly within an $8.6 \mathrm{~cm} \times 8.6 \mathrm{~cm}$ square in the center of the screen. These experimental assemblages closely mimicked the patchiness, compo- sition, richness, and biomass of macroalgal communities at nearby shallow subtidal field sites (Bruno et al. 2005). The screens were submerged in a dilute concentration of pesticide ('Sevin': 1-napthyl n-methylcarbamate) to remove small grazers and were then rinsed thoroughly and attached $30 \mathrm{~cm}$ below the water's surface in the mesocosms.

The common herbivorous amphipod Gammarus mucronatus was used as the experimental prey species. Gammarids are one of the most abundant mesograzers in estuarine ecosystems and are important prey for fishes and crustaceans (Hay \& Sutherland 1988, Duffy \& Hay 1990). G. mucronatus feeds mostly on microalgae and detritus (Zimmerman et al. 1979) and has little or no direct effect on macroalgae (Duffy et al. 2001). Amphipods were collected from macroalgae at local field sites, and 50 individuals were added to each mesocosm the day before the predator additions.

We used the mummichog Fundulus heteroclitus, a common fish of coastal habitats from Newfoundland to Florida (Kneib 1986), as the experimental predator. The young mummichogs used in this study are carnivorous and feed mainly on small crustaceans such as amphipods and polychaetes (Kneib \& Stiven 1978) during daylight hours (Weisberg et al. 1981). The experiment included 2 predator treatments: a no predator control and a predator addition consisting of 2 mummichogs $(1.4$ to $3.1 \mathrm{~g}$ each $=4.5 \pm 0.1 \mathrm{~g}$ [mean $\pm 1 \mathrm{SE}$ ] of predator biomass per mesocosm). Mummichogs were collected from nearby seagrass beds and were added to the mesocosms on the morning of June 16, 2007, and removed $9 \mathrm{~h}$ later. After removing the predators, we carefully collected and rinsed the algae and sieved the water from each mesocosm to recover all amphipods, which were immediately counted by hand.

The duration of the experiment was based on pilot studies and previous experiments (e.g. Bruno \& O'Connor 2005) that indicated that amphipod consumption by fish in mesocosms and in the field is rapid. The relatively short duration also limited potentially confounding effects of variation among algal species growth rates (which could lead to unintended covariance between algal biomass and identity/richness) and in situ prey reproduction, which could also be influenced by algal identity and richness. Amphipod abundances were log-transformed to meet statistical assumptions of normality and homogeneity of variance. A 1-factor ANOVA was conducted to determine if algal treatment affected amphipod recovery in the absence of predators, and a 2-factor ANOVA determined the effects of the algal and predator treatments on final prey abundances. We used least square means (LSM) planned contrasts to detect algal richness (via non-transgressive overyielding) and identity effects on 
the number of recovered amphipods in the presence of predators. In replacement designs (as in this experiment), non-transgressive overyielding can be detected by comparing the average response of all pooled monocultures to the response of the polyculture (Bruno et al. 2005).

Field experiment. We performed a similar and complementary field experiment in May 2006 in which we measured the effects of macroalgal richness on prey colonization in the presence of predators in a natural setting. Here we again created monocultures of 5 algal species and the mixture of those 5 species by securing the macroalgae to Vexar screens ( $\mathrm{n}=5$ for monocultures and 10 for polycultures). In addition to the 3 algal species used in the mesocosm experiment (Sargassum filipendula, Gracilaria verrucosa, and Ulva lactuca) we used Codium sp. and Enteromorpha sp. The field experiment also included an additional 3-species polyculture treatment in which algal identity in each of the 10 replicates was determined by randomly selecting a subset of the experimental species pool. After attaching the macroalgae and removing all prey (as described for the mesocosm experiment) the experimental algal screens were each secured to a separate cinder block. The blocks were placed on sandy substrata (1 to $2 \mathrm{~m}$ depth) $2 \mathrm{~m}$ from Radio Island Jetty, Radio Island, North Carolina, USA, a high current velocity estuarine site. Most of the algae and prey for both experiments were collected from this site. After $2 \mathrm{~d}$, prey that had naturally colonized the experimental algal communities (most likely from the algae on the nearby jetty) were collected by placing the algal screens in 1 gallon (3.8 l) Ziploc bags. The algae were then rinsed to remove prey, which were preserved in $70 \%$ ethanol, sorted by species, and counted. Algal richness and identity effects on Gammarus mucronatus abundance were examined using LSM planned contrasts for the monocultures and the 5-species polyculture as outlined for the mesocosm experiment. A linear regression was also conducted to examine the relationship between algal richness on G. mucronatus abundance using all algal richness treatments $(1,3$, and 5 algae species).

\section{RESULTS}

When predators were absent, we recovered over $90 \%$ of the herbivores at the conclusion of the mesocosm experiment. The algal treatment had no effect on prey recovery in these controls (Fig. 1; 1-factor ANOVA on all treatments without predators; $F=0.77, \mathrm{p}=0.58$ ). Adding predators reduced prey recovery on average (i.e. across treatments) by $50 \%$ (from 91.1 to $45.6 \%$ ), indicating that half of the amphipods were consumed

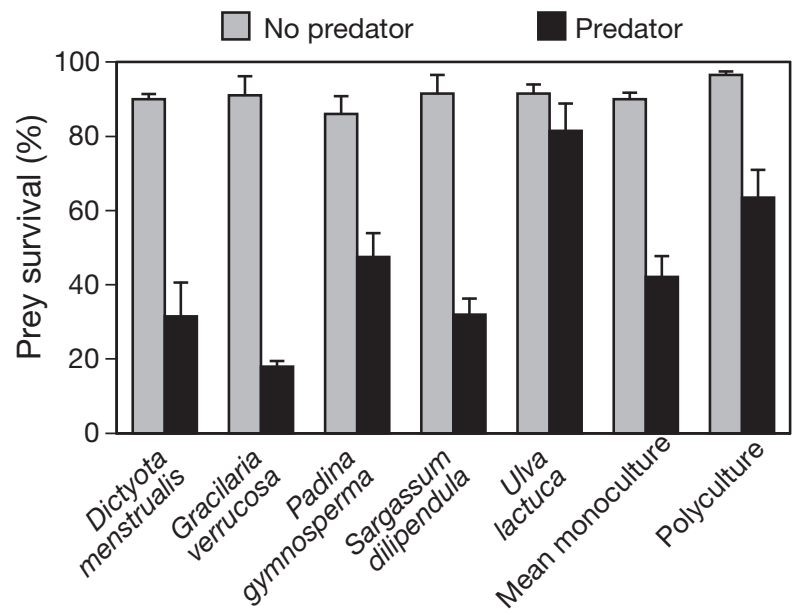

Fig. 1. Gammarus mucronatus. Effect of macroalgal identity and richness on predation intensity (Fundulus heteroclitus) in the mesocosm experiment. Values are means $\pm 1 \mathrm{SE} . \mathrm{n}=4$, except for the mean monoculture calculations, for which $\mathrm{n}=20$

during the $9 \mathrm{~h}$ experiment. Both factors (predator treatment, $F_{1,47}=107.57, \mathrm{p}<0.0001$; algal treatment, $F_{5,47}=$ $8.20, \mathrm{p}<0.0001)$ and the algal $\times$ predator treatment interaction $\left(F_{5,47}=7.63, \mathrm{p}<0.0001\right)$ were statistically significant. The number of amphipods recovered also differed significantly (LSM planned contrast: $\mathrm{p}=0.0008$ ) between the average of the algae monocultures (23.1 \pm 5.3 , mean $\pm 1 \mathrm{SE})$ and the polyculture $(31.8 \pm 3.7)$ when predators were present (Fig. 1), indicating that increasing macroalgal richness reduced predation intensity. Predation intensity was lowest in the Ulva lactuca monoculture, but the means of the U. lactuca monoculture and the polyculture treatments did not differ significantly $(p=0.37)$.

In the field experiment, there was a significant positive relationship between algal species richness and final Gammarus mucronatus abundance (Fig. 2A; linear regression analysis; $\left.p=0.006, r^{2}=0.20\right)$. The algal identity/richness treatment had a significant effect on final G. mucronatus density (Fig. $2 \mathrm{~B}_{;} F_{5,21}=6.18, \mathrm{p}=$ 0.001). However, because several algal screens were not recovered, this test was not balanced, and the results should be interpreted with caution. Amphipod density in the algal polycultures was significantly greater than that of the pooled monocultures $(\mathrm{p}=$ 0.002) but not different from Ulva lactuca, the monoculture with the highest prey density. Of the 6051 crustacean prey individuals recovered from the 36 algal screens, $52 \%$ were G. mucronatus (the rest were from 23 other amphipod species). We analyzed the results of the field experiment using total prey densities (i.e. the summed abundance of all species), and the results (not shown) were not qualitatively different from those based on G. mucronatus densities. 

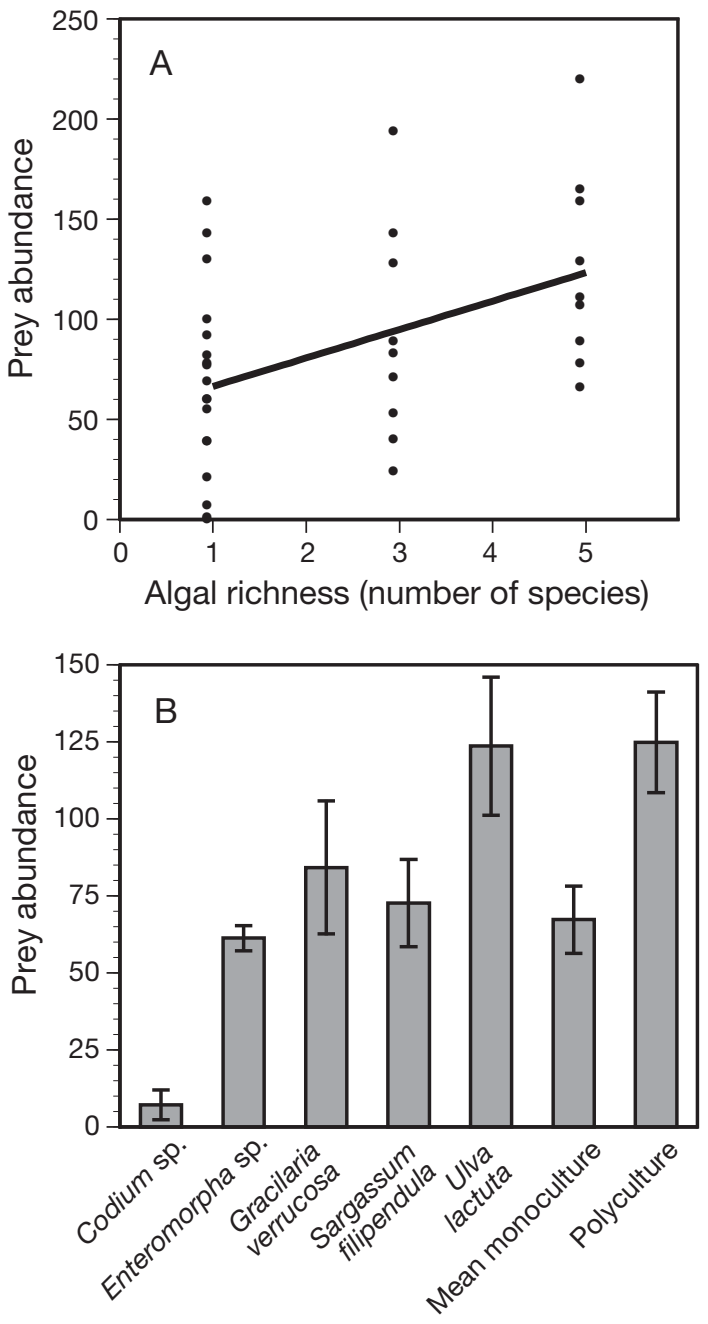

Fig. 2. Gammarus mucronatus. Effect of macroalgal (A) richness and (B) identity on prey abundance per screen $(25 \times$ $25 \mathrm{~cm}$ ) at the end of the field experiment. Values in (B) are means $\pm \mathrm{SE}$. Solid line: best fit linear regression

\section{DISCUSSION}

Several traits of habitat-forming or 'foundation' species determine the degree to which environmental stresses such as predation intensity are ameliorated (Bruno \& Bertness 2001). Our results indicate that the richness of foundation species could play an equally important ecological role. In both experiments, prey density varied substantially among algal species (i.e. an identity effect) and was significantly higher in the 5 species polycultures than in the average monoculture (i.e. a richness effect). In the mesocosm experiment, when predators were absent, prey survival (i.e. recovery) did not vary and was $>90 \%$. In contrast, when predatory fish were present, prey density was reduced by $50 \%$, and our analyses suggested that both the identity and richness of habitat-forming algae can have striking effects on grazer populations over relatively short time periods ( $9 \mathrm{~h}$ in this experiment).

The results of the field experiment support this interpretation; prey density was greater in the polyculture than the mean monoculture in the presence of a diverse guild of fish and invertebrate predators (Fig. 2B). We also analyzed the results of the field experiment with a regression analysis, treating macroalgal richness as a continuous variable; there was a significant positive relationship between algal richness and prey abundance (Fig. 2A). Because we did not include predator exclusion treatments in the field experiment, we cannot separate the effect of algal species-specific predation from other processes such as habitat selectivity and emigration by the grazers. However, the results of the mesocosm experiment suggest that this result could in part have been caused by the effect of algal richness on predation intensity, possibly by influencing predator search images and movements or prey behavior.

Parker et al. (2001) found that macrophyte composition, but not richness, significantly affected the abundance and biomass of epifaunal animal communities. Holmlund et al. (1990) also found that macroalgal identity significantly affected predation of the herbivorous amphipod Ampithoe longimana by pinfish, which varied with the morphology of habitat-forming macroalgae. Surprisingly, predation was lowest for sheet-like algal morphologies including Ulva lactuca and highest for blade-like morphologies such as Gracilaria verrucosa (Holmlund et al. 1990). In both of our experiments, more amphipod prey were recovered in $U$. lactuca monocultures than in any other algal monoculture. Although $U$. lactuca forms an essentially flat sheet, when naturally attached to the substrate it attains a complex, folded structure, which presumably offers increased refuge spaces for prey.

Given the strong effect of Ulva lactuca on predation intensity and prey density, it is likely that the observed richness effect was in part due to the inclusion of this species. However, in a replacement design (i.e. when total plant biomass is held constant across richness levels), the inclusion of strong interactors cannot explain observed richness effects. In other words, sampling effects alone (i.e. the probabilistic inclusion of a particular species), cannot mechanistically underlie the greater performance of polycultures compared to that of the average monoculture. This is because the abundance or biomass of the species in question is greatly reduced in polyculture. In our mesocosm experiment, $U$. lactuca wet biomass was $30 \mathrm{~g}$ in the polyculture yet only $6 \mathrm{~g}$ in the monoculture. If, in fact, the presence of $U$. lactuca alone in the polycultures drove the observed reduction in predation, then this increase in the per capita (or per biomass) effect could be attributable to a 
richness effect, caused perhaps by the reduction in intra-specific competition in diverse polycultures (Bruno $\&$ O'Connor 2005). On the other hand, perhaps the role of $U$. lactuca in repelling predators and facilitating prey is entirely decoupled from its abundance. Though plausible, this seems unlikely, and it would suggest that the observed richness effect in our experiment is attributable largely to sampling effects (Huston 1997).

Alternatively, the richness effect could be due to increased habitat complexity in the polyculture, resulting in decreased predation efficiency. Larger algal and seagrass blades provide more protection to amphipods than thinner, more branched blades (Stoner 1982, Edgar 1983), possibly because larger surface areas decrease the visual contrast between an amphipod and its background (Holmlund et al. 1990). The combination of several, morphologically distinct plant species in our polycultures may have decreased prey contrast, effectively preventing the formation of a search image by predators or by interrupting the predator's normal search pattern (Andow \& Prokym 1990). Aquilino et al. (2005) also found that increasing plant richness decreased predation on an insect herbivore, though this resulted from the inclusion of a structurally simple plant, which likely enhanced the herbivore's ability to detect and evade predators. These proposed mechanisms resulting from complex and simple structures of habitat-forming species deserve further attention to determine how and when richness in primary producers affects predation rates, especially in the presence of a diverse guild of prey species.

Most manipulations of macroalgal species richness have found that it has little or no effect on primary production (Bruno et al. 2005, Stachowicz et al. 2007, but see Bruno et al. 2008). But what if we are measuring the wrong parameters? Due to the intensity of predation in many benthic marine communities and the great variety of other primary producers (e.g. microalgae, phytoplankton, and so forth) in aquatic ecosystems, perhaps the main effect of macroalgal richness lies in the regulation of trophic dynamics, energy transfer, and other higher-order and indirect interactions and ecosystem functions. Even in terrestrial communities, changes in plant richness are typically viewed as having weaker effects on primary productivity than changes in higher trophic levels (Shurin et al. 2002). However, if plant richness has comparable effects on trophic interactions in other communities, we may be greatly underestimating the importance of plant biodiversity on food webs and ecosystem processes.

Acknowledgements. We are grateful to C. Brown and S. Lee for providing technical assistance and intellectual input. We also thank the staff at the Institute of Marine Sciences. This research was funded by grants from the National Science Foundation (USA)(OCE0326983 and OCE0327191) to J.F.B.

\section{LITERATURE CITED}

Andow DA, Prokym DR (1990) Plant structural complexity and host-finding by a parasitoid. Oecologia 82:162-165

Aquilino KM, Cardinale BJ, Ives AR (2005) Reciprocal effects of host plant and natural enemy diversity on herbivore suppression: an empirical study of a model tritrophic system. Oikos 108:275-282

Bruno JF, Bertness MD (2001) Habitat modification and facilitation in benthic marine communities. In: Bertness MD, Gaines SD, Hay ME (eds) Marine community ecology. Sinauer, Sunderland, MA, p 201-218

Bruno JF, O'Connor MI (2005) Cascading effects of predator diversity and omnivory in a marine food web. Ecol Lett 8:1048-1056

Bruno JF, Stachowicz JJ, Bertness MD (2003) Inclusion of facilitation into ecological theory. Trends Ecol Evol 18: 119-125

Bruno JF, Boyer KE, Duffy JE, Lee SC, Kertesz JS (2005) Effects of macroalgal species identity and richness on primary production in benthic marine communities. Ecol Lett 8:1165-1174

Bruno JF, Boyer KE, Duffy JE, Lee SC (2008) Relative and interactive effects of plant and grazer richness in a benthic marine community. Ecology 89:2518-2528

> Cardinale BJ, Srivastava DS, Duffy JE, Wright JP, Downing AL, Sankaran M, Jouseau C (2006) Effects of biodiversity on the functioning of trophic groups and ecosystems. Nature 443:989-992

Diehl S (1992) Fish predation and community structure: the role of omnivory and habitat complexity. Ecology 73: 1646-1661

> Duffy JE, Hay ME (1990) Seaweed adaptations to herbivory. Bioscience 40:368-375

Duffy JE, Hay ME (2000) Strong impacts of grazing amphipods on the organization of a benthic community. Ecol Monogr 70:237-263

Duffy JE, Macdonald KS, Rhode JM, Parker JD (2001) Grazer diversity, functional redundancy, and productivity in seagrass beds: an experimental test. Ecology 82:2417-2434

- Edgar GJ (1983) The ecology of south-east Tasmanian phytal animal communities. IV. Factors affecting the distribution of ampithoid amphipods among algae. J Exp Mar Biol Ecol 70:205-225

Hay ME, Sutherland JP (1988) The ecology of rubble structures of the South Atlantic Bight: a community profile. United States Fish and Wildlife Service, Department of the Interior, Washington, DC

Heck KL, Orth RJ (1980) Seagrass habitats: the roles of habitat complexity, competition and predation in structuring associated fish and motile macroinvertebrate assemblages. In: Kennedy VS (ed) Estuarine perspectives. Academic Press, New York, p 449-646

Heck KL, Wetstone GS (1977) Habitat complexity and invertebrate species richness and abundance in tropical seagrass meadows. J Biogeogr 4:135-142

Holmlund MB, Peterson CH, Hay ME (1990) Does algal morphology affect amphipod susceptibility to fish predation? J Exp Mar Biol Ecol 139:65-83

> Huston MA (1997) Hidden treatments in ecological experiments: re-evaluating the ecosystem function of biodiversity. Oecologia 110:449-460

Hutchinson GE (1959) Homage to Santa Rosalia or why are there so many kinds of animals? Am Nat 93:145-159

Kneib RT (1986) The role of Fundulus heteroclitus in salt marsh trophic dynamics. Am Zool 26:259-269 
Kneib RT, Stiven AE (1978) Growth, reproduction, and feeding of Fundulus heteroclitus (L.) on a North Carolina salt marsh. J Exp Mar Biol Ecol 31:121-140

Loreau M (1998) Separating sampling and other effects in biodiversity experiments. Oikos 82:600-602

Murdoch WW, Evans FC, Peterson CH (1972) Diversity and pattern in plants and insects. Ecology 53:819-829

Olson MH, Jacobs RP, O'Donnell EB (2007) Species diversity enhances predator growth rates. Research Letters in Ecology, Vol 2007. Hindawi Publishing, New York, NY

Parker JD, Duffy JE, Orth RJ (2001) Plant species diversity and composition: experimental effects on marine epifaunal assemblages. Mar Ecol Prog Ser 224:55-67

Pimentel D (1961) Species diversity and insect population outbreaks. Ann Entomol Soc Am 54:76-86

Price PW, Bouton CE, Gross P, McPheron BA, Thompson JN, Weis AE (1980) Interactions among three trophic levels: influence of plants on interactions between insect herbivores and natural enemies. Annu Rev Ecol Syst 11:41-65

Shurin JB, Borer ET, Seabloom EW, Anderson K and others (2002) A cross-ecosystem comparison of the strength of trophic cascades. Ecol Lett 5:785-791

Siemann E (1998) Experimental tests of effects of plant productivity and diversity on grassland arthropod diversity.

Editorial responsibility: Romuald Lipcius,

Gloucester Point, Virginia, USA
Ecology 79:2057-2070

Siemann E, Tilman D, Haarstad J, Ritchie M (1998) Experimental tests of the dependence of arthropod diversity on plant diversity. Am Nat 152:738-750

Southwood TRE, Brown VK, Reader PM (1979) The relationship of plant and insect diversities in succession. Biol J Linn Soc 12:327-348

Stachowicz JJ, Bruno JF, Duffy JE (2007) Understanding the effects of marine biodiversity on communities and ecosystems. Annu Rev Ecol Evol Syst 38:739-766

Stoner AW (1982) The influence of benthic macrophytes of the foraging behavior of pinfish Lagodon rhomboides (Linnaeus). J Exp Mar Biol Ecol 58:271-284

Strong DR, Lawton JH, Southwood TRE (1984) Insects on plants. Harvard University Press, Cambridge, MA

Weisberg SB, Whalen R, Lotrich VA (1981) Tidal and diurnal influence on food consumption of a salt marsh killifish Fundulus heteroclitus. Mar Biol 61:243-246

> Yachi S, Loreau M (1999) Biodiversity and ecosystem productivity in a fluctuating environment: the insurance hypothesis. Proc Natl Acad Sci USA 96:1463-1468

> Zimmerman R, Gibson R, Harrington J (1979) Herbivory and detrivory among gammaridean amphipods from a Florida seagrass community. Mar Biol 54:41-47

Submitted: October 9, 2008; Accepted: November 8, 2009

Proofs received from author(s): February 1, 2010 